\title{
Age-related synaptic loss of the medial olivocochlear efferent innervation
}

\author{
Benjamin Fu', Colleen Le Prell ${ }^{2}$, Dwayne Simmons ${ }^{3}$, Debin Lei ${ }^{1}$, Angela Schrader ${ }^{1}$, Amelia B Chen', \\ Jianxin Bao ${ }^{1,4,5^{*}}$
}

\begin{abstract}
Age-related functional decline of the nervous system is consistently observed, though cellular and molecular events responsible for this decline remain largely unknown. One of the most prevalent age-related functional declines is age-related hearing loss (presbycusis), a major cause of which is the loss of outer hair cells (OHCs) and spiral ganglion neurons. Previous studies have also identified an age-related functional decline in the medial olivocochlear (MOC) efferent system prior to age-related loss of OHCs. The present study evaluated the hypothesis that this functional decline of the MOC efferent system is due to age-related synaptic loss of the efferent innervation of the OHCs. To this end, we used a recently-identified transgenic mouse line in which the expression of yellow fluorescent protein (YFP), under the control of neuron-specific elements from the thy 1 gene, permits the visualization of the synaptic connections between MOC efferent fibers and OHCs. In this model, there was a dramatic synaptic loss between the MOC efferent fibers and the OHCs in older mice. However, age-related loss of efferent synapses was independent of $\mathrm{OHC}$ status. These data demonstrate for the first time that age-related loss of efferent synapses may contribute to the functional decline of the MOC efferent system and that this synaptic loss is not necessary for age-related loss of OHCs.
\end{abstract}

\section{Background}

Functional decline of the nervous system is a cardinal feature of normal aging [for recent review, [1,2]]. Agerelated hearing loss (presbycusis) is the third most prevalent condition of elderly persons, exceeded only by arthritis and hypertension, with approximately $97 \%$ of people experiencing a decline in hearing during aging $[3,4]$. Presbycusis is also characterized by reduced speech understanding in noisy environments, slowed central processing of acoustic information, and impaired sound localization. In human presbycusis, a pattern of progressive hearing loss typically starts at the high frequencies. This pattern is also observed in C57BL/6J inbred mice, a well-studied animal model for presbycusis [5]. The age-related functional decline of hearing corresponds to a loss of outer hair cells (OHCs) and spiral ganglion neurons in the basal region of the cochlea. However, little is known about possible cellular and molecular mechanisms underlying these age-related

\footnotetext{
* Correspondence: jbao@wustl.edu

1 Department of Otolaryngology, Washington University, St. Louis, MO, 63110, USA

Full list of author information is available at the end of the article
}

cell losses [for review, [5-8]]. Recently, age-related synaptic loss between inner hair cells (IHCs) and spiral ganglion neurons (SGNs) has been found prior to agerelated SGN loss, although there is no direct link between the synaptic loss and the loss of SGN during aging [9]. Interestingly, a series of studies have clearly demonstrated an age-related functional decline of the medial olivocochlear efferent (MOC) system prior to OHC degeneration both in humans and mice [10-13]. This age-related change of the MOC efferent system could contribute to the greater difficulty experienced by elderly individuals when listening in noisy environments because the MOC most likely is evolved in "unmasking" biologically important acoustic signals by reducing the response of the cochlea to simultaneous low-level noises [14-16]. However, the possible cellular and molecular mechanisms underlying this functional decline are unknown.

The auditory efferent system to the cochlea consists of two major divisions: the MOC pathway and the lateral olivocochlear (LOC) pathway [17-19]. The LOC system originates in the lateral nuclei of the superior olivary complex and forms axodendritic synapses on afferent 
dendrites of type-I spiral ganglion neurons below IHCs. Although function of the LOC system is not well understood, it may contribute to the modulation of auditory nerve activity [20,21]. The MOC pathway, comprising thick myelinated nerve fibers, originates from neurons within medial and ventral regions of the superior olivary complex and makes large axosomatic synapes with OHCs (DAdditional file 1: Diagram 1). This innervation can be demonstrated by cholinergic markers [22,23]. Extensive studies have clearly demonstrated that the activation of the MOC system attenuates cochlear responses to acoustic stimulation [24-33]. This attenuation is convincingly shown arising from cholinergic innervations of the MOC synapses on $\mathrm{OHCs}$ via the $\alpha 9$ nicotinic cholinergic receptors [15,34]. In both humans and animal models, the strength of the MOC efferent innervation can be measured by the degree of contralateral attenuation of otoacoustic emissions (OAE), particularly distortion product OAEs (DPOAES) [35-38], or ipsilateral DPOAE adaptation $[39,40]$. Using in vivo functional assays, age-related functional decline of the MOC system has been well documented both in human and animals [10-13,41]. However, it is unclear whether this age-related functional decline is due to age-related loss of OHC or loss of MOC synapses on OHCs. Recently, we has discovered that MOC terminals on $\mathrm{OHCs}$ can be visualized in one line of transgenic mice in which the expression of yellow fluorescent protein (YFP) is under the control of neuron-specific elements from the thy 1 gene [42]. Therefore, this animal model provided us with an opportunity to directly address whether there is an age-related loss of MOC terminals in the cochlea, and whether this loss occurs prior to the loss of OHCs.

\section{Results}

Characterization of YFP-12 mice for the MOC synapses on $\mathrm{OHCs}$

Certain neuronal populations and their synaptic terminals are well labeled in transgenic mouse lines with Yellow Fluorescent Protein (YFP) expression under the control of neuron-specific elements from the thy 1 gene [42] We examined four such transgenic lines and discovered one line, the YFP-12 line, which has well-labeled synaptic terminals underneath both the IHCs and the OHCs (Figure 1A). OHCs receive synaptic innervation from both MOC efferent neurons and type-II SGNs. These YFP-positive terminals were thus immunostained with an antibody against VAChT, a reliable cholinergic marker for MOC synapses, to determine the extent of these synapses. From the whole-mount horizontal sections, we observed a substantial overlap between the distribution of YFP-positive and VAChT-positive synapses on OHCs (Figure 1B).
A

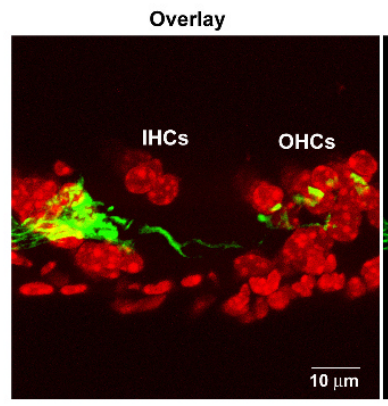

B

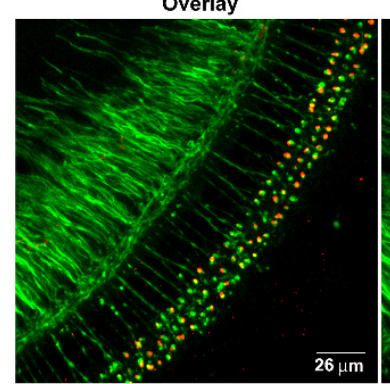

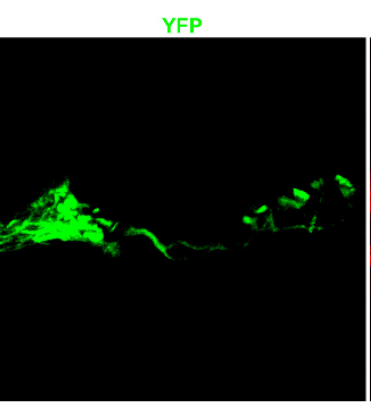

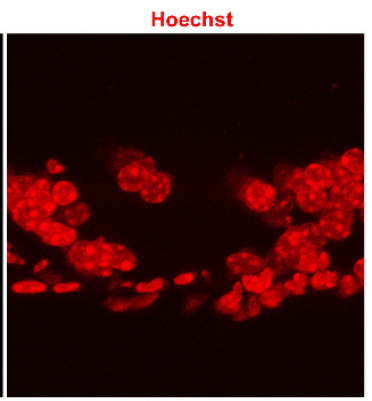

YFP

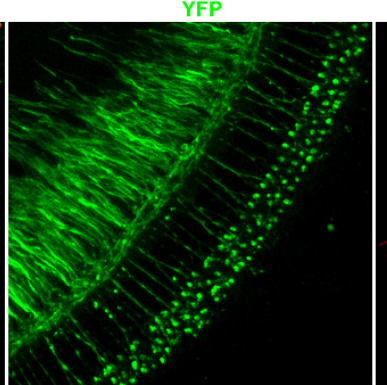

VAChT

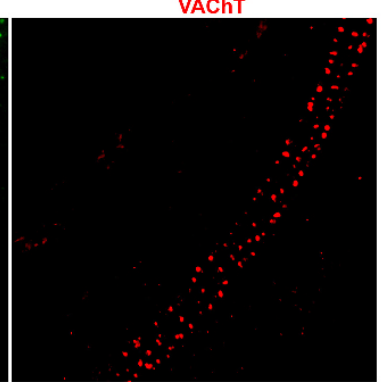

Figure 1 The MOC efferent innervation in the cochlea of YFP-12 transgenic mice. (A) A sagittal cochlear section from one 2-month old YFP-12 mouse with the Hoechst staining for nuclei (red) and YFP (green). (B) A wholemount cochlea from one 2-month-old YFP-12 mouse immunostained with an antibody against VAChT (Red). 
To precisely determine whether each YFP-positive terminal was also VAChT-positive (whole length of the cochlear spiral shown in Figure 2A), we focused on two frequency regions during which presbycusis proceeds at different rates $[5,43]$. Based on previous findings of DPOAE and contralateral DPOAE suppression tests [44], age-related loss of MOC function in C57BL/6J mice begins around 2 months of age. Since this agerelated functional decline is much smaller at $10 \mathrm{kHz}$ than at 20 to $30 \mathrm{kHz}$, we focused on the $10 \mathrm{kHz}$ and 28 $\mathrm{kHz}$ regions of the cochlea. Confocal images at these two frequency regions are shown in Figure 2B. Nearly all YFP-positive terminals were also VAChT-positive at both 10 and $28 \mathrm{kHz}$ regions in the 2-month-old mice; however, a few YFP-positive terminals below OHCs did not colocalize with VAChT. We counted both YFP-positive and VAChT-positive terminals below $\mathrm{OHCs}$ at the $10 \mathrm{kHz}$ and $28 \mathrm{kHz}$ regions (about $45 \mathrm{OHCs}$ for each region). At the $10 \mathrm{kHz}$ region (Figure $2 \mathrm{C}$ ), the ratio of YFP-positive terminals to OHCs was about 0.99 for the first row of $\mathrm{OHCs}(\mathrm{OHC} 1)$ and 0.98 for the second and third $\mathrm{OHC}$ rows. The ratio of VAChT-positive terminals to $\mathrm{OHCs}$ was about 0.87 for the first $\mathrm{OHC}$ row, 0.96 for the second row, and 0.85 for the third row. The ratio of VAChT-labeled terminals and YFP-VAChT double labeled terminals were the same, suggesting that all VAChT labeled terminals colocalized with YFP. Only about one or two YFP-positive terminals per $45 \mathrm{OHCs}$ did not appear together with VAChT. This could be the result of innervations from type-II SGNs or MOC fibers not expressing VAChT. At the $28 \mathrm{kHz}$ region (Figure 2D), virtually all YFP-labeled terminals below OHCs colocalized with VAChT and all OHCs had at least one YFP-labeled terminal. The ratio between YFP- and VAChT-positive terminals and OHCs was 1.00 for the first and second rows of OHCs. The ratio was also 1.00 for two out of three mice for the third row of OHCs. In one case, there were no YFP- or VAChT-positive terminals below two OHCs.

\section{Age-related loss of the MOC synapses in the cochlea}

Prior to examining possible age-related loss of MOC efferent synapses underneath $\mathrm{OHCs}$ in animals from the YFP-12 transgenic line, audio brainstem responses (ABRs) were conducted on young (2-month-old) and old (12-month-old) YFP-12 mice (Figure 3). Animals at both young and old ages had the lowest hearing thresholds at $10 \mathrm{kHz}$, with increasing thresholds for higher frequencies. Although all frequency regions experienced elevated thresholds due to age, as expected for $\mathrm{C} 57 \mathrm{BL} / 6 \mathrm{~J}$ mice, greater hearing loss occurred at higher frequencies than at lower frequencies. The ABR threshold shift between 2-month-old and 12 -month-old mice at $10 \mathrm{kHz}$ region was approximately $26 \mathrm{~dB}\left(p=2.79 \times 10^{-5}\right)$, while the shift was about $50 \mathrm{~dB}$ at $28 \mathrm{kHz}\left(p=6.73 \times 10^{-9}\right)$.

In order to assess age-related loss of the MOC synapses below OHCs, confocal images were taken of the 10 and $28 \mathrm{kHz}$ frequency regions in 12-month-old mice (Figure 4A). To monitor possible loss of OHCs, we also labeled $\mathrm{OHC}$ bundles with phalloidin. At the 10 $\mathrm{kHz}$ region, there was no obvious $\mathrm{OHC}$ loss, and the distribution of YFP-positive synapses underneath $\mathrm{OHCs}$ was comparable to mice at 2 months. At the $28 \mathrm{kHz}$ region, age-related loss of OHCs was minimal. However, a substantial decrease of YFP-positive terminals was observed in this region, in spite of survival of OHCs. We quantified the number of YFP-positive terminals for 2 - and 12-month-old mice at the 10 and $28 \mathrm{kHz}$ regions. In the $10 \mathrm{kHz}$ region (Figure $4 \mathrm{~B}$ ), the only significant $(\mathrm{p}<0.005)$ difference between 2- and 12month-old mice in the number of YFP-positive synapses was found in the third row of OHCs. There was roughly a $13 \%$ decline in efferent terminals at the third row of OHCs. In contrast to the $10 \mathrm{kHz}$ region, the $28 \mathrm{kHz}$ region demonstrated a more dramatic decline in efferent synapses among all $\mathrm{OHC}$ rows in 12-month-old mice (Figure 4C). Age-related loss of the MOC synapses was $75 \%$ in the first row, $65 \%$ in the second row, and $63 \%$ in the third row.

\section{No correlation between age-related OHC loss and the loss of MOC synapses}

By using a confocal microscope to scan the wholemount cochlear sections from the top of hair bundles to the nuclei of Deiters' cells at an interval of $0.96 \mu \mathrm{m}$, we observed three types of age-related loss of MOC synapses (Figure 5A). The first type was a loss of both $\mathrm{OHCs}$ and the MOC synapses that would have previously contacted the missing OHCs. The second was a loss of MOC synapses despite the presence of intact $\mathrm{OHCs}$, which suggests that either survival of OHCs is not dependent on MOC innervation or MOC synaptic degeneration was recent enough that $\mathrm{OHC}$ survival had not yet been compromised. The third type of age-related change was the presence of MOC synapses despite $\mathrm{OHC}$ death. Because of the 3-D nature of the organ of Corti, it was initially difficult to distinguish whether the MOC synapse was at the previous level of the $\mathrm{OHC}$ or if it had withdrawn to the level of the Deiters' cells. Thus, we examined the third type in more detail. In Figure 5B, an overlay at the $10 \mathrm{kHz}$ region clearly shows one missing $\mathrm{OHC}$ with an MOC synapse - the result of the angle of OHCs at the 3-D overlay. We then focused on the compact $\mathrm{OHC}$ nuclei as reliable markers, since they lie closer to MOC synapses. After examining every optical section at about $116 \mu \mathrm{m}$ from the hair bundles, the $\mathrm{MOC}$ synapse appeared underneath the missing $\mathrm{OHC}$, 


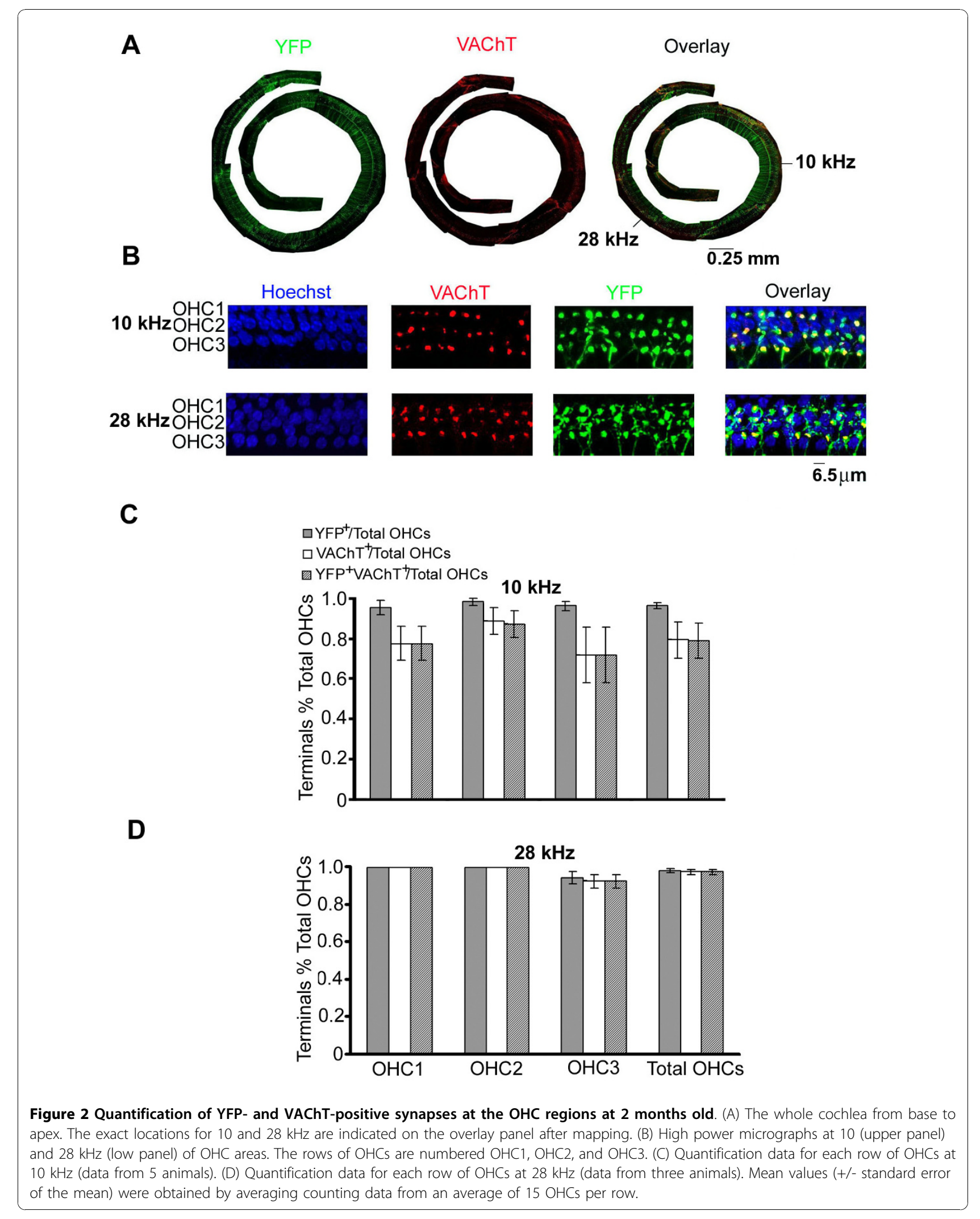




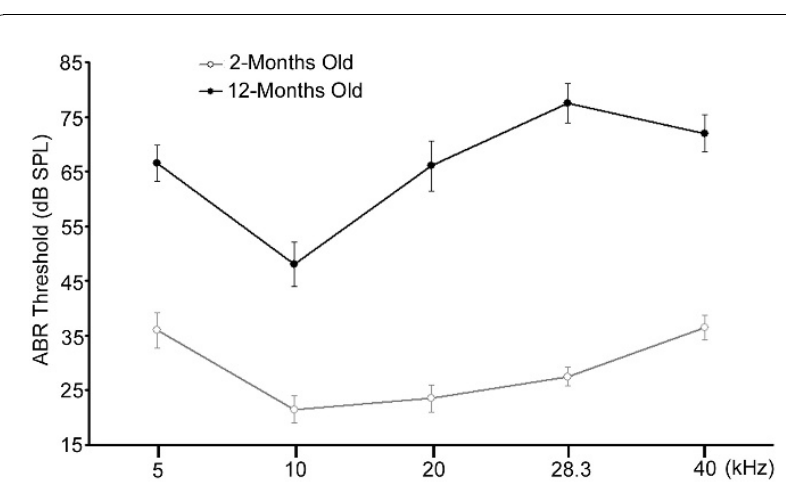

Figure 3 ABR thresholds for 2- and 12-month-old YFP-12 mice under the $\mathrm{C} 57 \mathrm{BL} / 6 \mathrm{~J}$ genetic background. $\mathrm{ABR}$ thresholds (Mean \pm S.D) for 2-month-old mice ( $n=7$; grey line) were significantly lower than the thresholds (Mean \pm S.D) from 12-month-old mice ( $n=7$; black line).

and its intensity was similar to the MOC innervation on the right neighbor $\mathrm{OHC}$ (The middle panel of Figure 5C). Thus, the loss of OHCs and loss of MOC synapses could each occur independently.

\section{Discussion}

Possible causes of age-related functional decline of both the central and peripheral nervous system (CNS and PNS) are still not completely understood. Because extensive neuronal death is observed in age-related neurodegenerative diseases, it was proposed that neuronal death might also contribute to normal age-related functional decline of the nervous system [45-47]. However, in the CNS, loss of synapses rather than loss of neurons may be the major cause of age-related functional decline [48-50]. In the PNS, however, age-related loss of both synapses and neurons significantly contributes to functional decline [51-53]. In the cochlea, age-related loss of hair cells and spiral ganglion neurons are a major contributor to presbycusis although possible cellular and molecular mechanisms underlying the death of these cells are still unknown $[2,4,45]$. Recent data have strongly suggested the contribution of the MOC efferent system to age-related hearing loss [10-13,41]. In the present study, our results have showed for the first time that age-related loss of efferent terminals on OHCs occurs in C57BL/6J mice. Furthermore, we have found that age-related loss of the efferent $\mathrm{OHC}$ terminals and $\mathrm{OHCs}$ can occur independently, which suggests possibly a separate mechanism contributing to the age-related changes of these two biological structures.

In the cochlea, previous studies have clearly demonstrated synaptic loss between SGNs and IHCs, and withdrawal of SGN afferent fibers occur prior to SGN death during aging $[9,54,55]$. These data imply that SGN degeneration starts at its synapse with IHCs, and progress toward the cell body [9], although no evidence is currently able to prove conclusively that this synaptic loss was the actual cause of age-related SGN loss. In the MOC efferent system, extensive data collected from non-invasive functional testing clearly demonstrated age-related functional decline of the MOC system. Particularly, contralateral suppression of DPOAEs by the MOC efferent system is absent at middle ( 15 to $30 \mathrm{kHz}$ ) and high (30 - 45) frequencies in C57BL mice by eight weeks old [13]. Interestingly, our finding shows that every $\mathrm{OHC}$ still receives the MOC innervation at the 28 $\mathrm{kHz}$ region at 2 months old. This suggests that MOC neurotransmission at this synapse may be nonfunctional. Because most of the terminals are lost by 12 months old, it is possible that the MOC efferent synapses may lose function such as synaptic transmission before they are eliminated with aging. If this scenario is true, we would expect nearly all of MOC efferent terminals to be present even at 22 months in $\mathrm{CBA} / \mathrm{CaJ}$ mice because the MOC suppression just starts to differ from young animals [12]. Thus, in the future, it would be necessary to place the YFP-12 transgene into the $\mathrm{CBA} / \mathrm{CaJ}$ genetic background.

Morphologically, it seems that age-related loss of the MOC efferent terminals does not depend on OHCs because most of the terminal loss occurs prior to agerelated loss of OHCs. However, age-related functional changes in hair cells could contribute to this dramatic loss of MOC terminals in C57BL/6J mice. For example, studies have shown that abnormal tip link structure of the hair bundle results from a cadherin 23 mutation in C57BL/6J mice and may lead to a defective mechanoelectrical transduction apparatus [56]. This abnormal mechanoelectrical transduction may lead to or be associated with cumulative changes in either synaptic transmission between OHCs and efferent terminals or in abnormalities that affect slow motility but not the prestin-based electromotility. The presence of a few MOC terminals without $\mathrm{OHCs}$ at the $28 \mathrm{kHz}$ region from 12 months old mice seems to suggest that efferent terminals can survive the loss of OHCs. If similar phenomena are also observed in $\mathrm{CBA} / \mathrm{CaJ}$ mice, it would further indicate that age-related loss of $\mathrm{OHCs}$ and the MOC terminals are two independent processes.

\section{Conclusion}

Extensive synaptic and neuronal loss contributes to the pathology of age-related neurodegenerative diseases such as Alzheimer's disease [50,57]. It is important to address the question of whether synaptic loss during aging is the cause or the result of neuronal loss. Our data suggest also a third possibility, a parallel independent biological process for age-related loss of neurons and synapses. Because neuronal aging is the common 


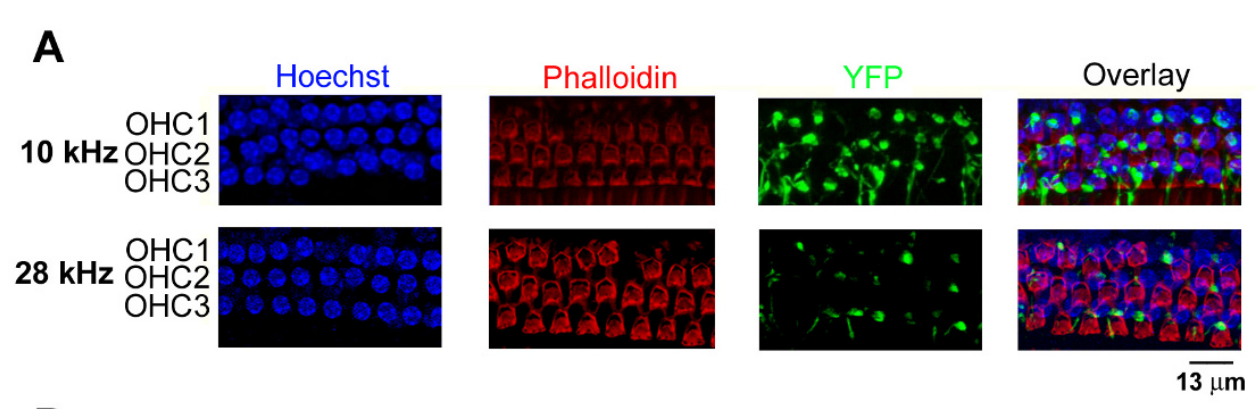

B

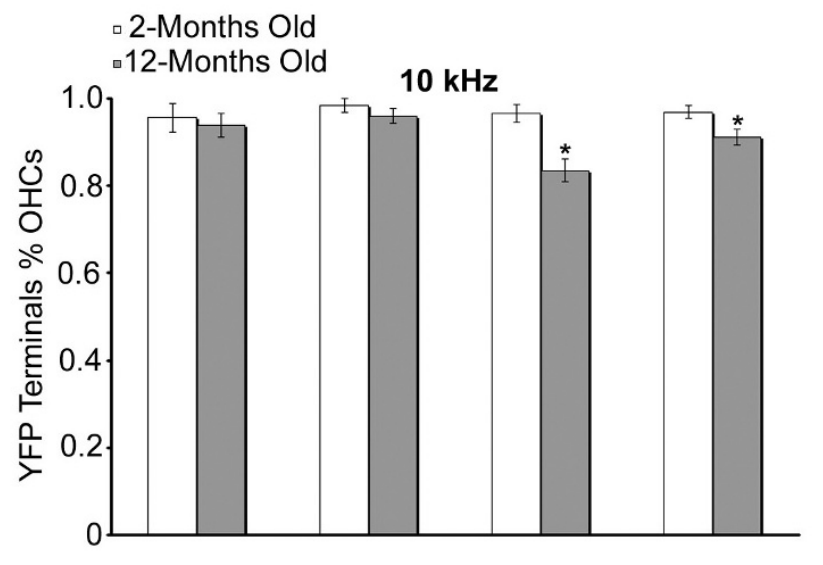

C

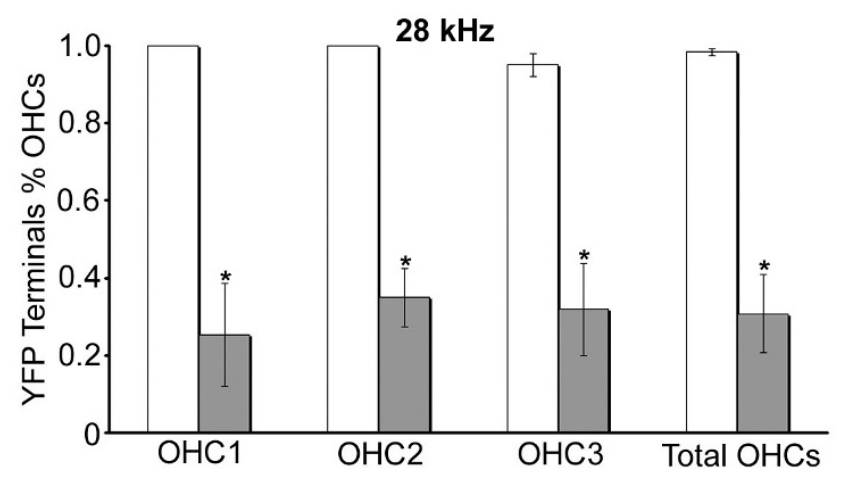

Figure 4 Age-related loss of the MOC synapses. (A) OHCs were labeled with both Hoechst and phalloidin, and the MOC synapses with YFP. (B) Quantification data for 2- and 12-month-old mice at $10 \mathrm{kHz}$ (data from three animals for each age group). (C) Quantification data for 2-and 12-month-old mice at $28 \mathrm{kHz}$ (data from three animals for each age group). Mean values (+/- standard error of the mean) were obtained by averaging counting data from an average of $15 \mathrm{OHCs}$ per row.

predisposing factor for neurodegenerative diseases, this possibility is worth exploring. In addition, our data provide the first morphological basis for age-related functional decline of the MOC efferent system in the cochlea: age-related loss of the MOC terminals.

\section{Methods}

\section{Animals}

The YFP-12 transgenic line was kindly provided by Joshua Sanes. This line was back-crossed over 10 generations to the $\mathrm{C} 57 \mathrm{BL} / 6 \mathrm{~J}$ genetic background. Mice were housed five per cage with food and water available. They were maintained in a noise-controlled environment on a $12 \mathrm{hr}$ light/dark cycle, with light onset at 6:00 a.m. All procedures here followed NIH guidelines and were approved by the animal care and use committee of Washington University.

\section{ABR Recording}

Mice were anesthetized ( $80 \mathrm{mg} / \mathrm{kg}$ ketamine, $15 \mathrm{mg} / \mathrm{kg}$ xylazine, i.p.) and positioned dorsal side up in a custom headholder. Core temperature was maintained at $37^{\circ} \mathrm{C}$ 


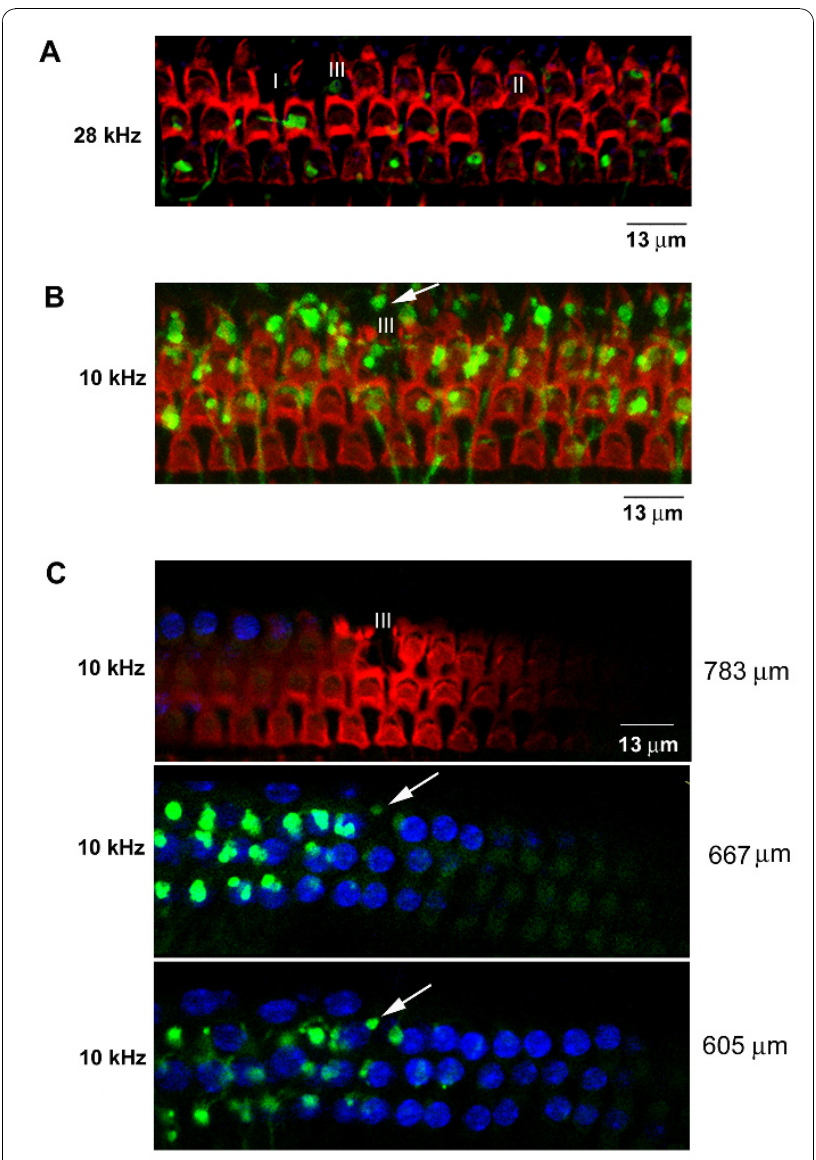

Figure 5 Correlation between age-related loss of $\mathrm{OHC}$ and the MOC synapses. (A) One overlay of confocal images at $28 \mathrm{kHz}$ from one 12-month-old YFP-12 mouse with the phalloidin staining for hair bundles (red) and YFP (green). Missing MOC synapse and OHCs were easily detected. (B) One overlay of confocal images at $10 \mathrm{kHz}$ from one 12-month-old YFP-12 mouse with the phalloidin staining for hair bundles (red) and YFP (green). One missing OHC was observed. (C) These panels are from the same regions as (B). The top panel shows the layer of hair bundles and the appearance of $\mathrm{OHC}$ nuclei on the left side, which is closer to the lens than the right side. The middle and bottom panels show the MOC synapse at the location of one missing $\mathrm{OHC}$.

using a thermostatically controlled heating pad in conjunction with a rectal probe (Yellow Springs Instruments Model 73A). Platinum needle electrodes (Grass) were inserted subcutaneously just behind the right ear (active), at the vertex (reference), and in the back (ground). Electrodes were led to a Grass P15 differential amplifier (0.1-10 kHz, X100), to a custom broadband amplifier $(0.1-10 \mathrm{kHz}, \mathrm{X} 1000)$, then digitized at $30 \mathrm{kHz}$ using a Cambridge Electronic Design micro1401, in conjunction with SIGNAL and custom signal averaging software, operating on a $120 \mathrm{MHz}$ Pentium PC. Sine wave stimuli generated by a Hewlett Packard 3325a digital oscillator were shaped by a custom electronic switch to $5 \mathrm{~ms}$ total duration, including $1 \mathrm{~ms}$ rise/fall times. The stimuli were amplified by a Crown D150A power amplifier and led to an Alpine SPS-OEOA coaxial speaker located $10 \mathrm{~cm}$ directly lateral to the right external auditory meatus. Stimuli were presented free field and calibrated using a B\&K 4135 1/4 inch microphone placed where the pinna would normally be. Toneburst stimuli at each frequency and level were presented 1000 times at $20 / \mathrm{s}$. The minimum sound pressure level required for a response (short-latency negative wave) was determined at $5.0,10.0,20.0,28$, and $40.0 \mathrm{kHz}$, using a $5 \mathrm{~dB}$ minimum step size. The sound level was increased in $5 \mathrm{~dB}$ steps and terminated at $101 \mathrm{~dB}$.

\section{Histological Analysis}

Mice were perfused transcardially with cold $2 \%$ paraformaldehyde and $2 \%$ glutaraldehyde in phosphate-buffered saline (PBS). Each cochlea was rapidly isolated, immersed in the same fixative, and the stapes immediately removed. Complete infiltration of the cochlea by fixative was ensured by making a small hole at the apex of the cochlear capsule and gently circulating the fixative over the cochlea using a transfer pipette. After overnight decalcification in sodium EDTA, cochleae were embedded in an agarose mold and cut in $200 \mu \mathrm{m}$ slices perpendicular to the cochlear axis. Cochlear slices were mounted on a glass slide with a coverslip using Mountquick “AQUEOUS” (Daido Sangyo Co. Ltd. Japan). The entire length of the cochlea was measured using a stereological analysis program (StereoInvestigator, MicroBrightField Inc.) on a computer connected to a Nikon Eclipse TE2000-U inverted microscope. To obtain a consistent measurement, we set the focus on the top of inner pillar cells for each section. After the whole length was obtained, a frequency-place map for the cochlea was calculated based the published formula [13]. Sections containing $10 \mathrm{kHz}$ and $28 \mathrm{kHz}$ regions (about $42.5 \%$ and $70 \%$ from the apex respectively) were processed for immunocytochemistry.

\section{Immunocytochemistry}

Immunostaining was carried out similar to our previous studies [58] Cochlear sections were washed with $1 \times$ PBST (0.1 M PBS in 0.1\% Tween 20) three times 10 minutes each and blocked with $10 \%$ normal goat serum (NGS; company) in $1 \times$ PBST for one hour. The sections were incubated with a rabbit antibody against the vesicular acetylcholine transporter (VAChT) (Sigma, St. Louis, MO) at 1:200 dilution in 3\% NGS overnight at $4^{\circ}$ C. The sections were then washed four times $10 \mathrm{~min}$ utes each in PBST. A 1:250 solution of goat anti-rabbitCY3 was then added. Cochlear slices were washed with PBST four more times before mounting. In certain cases, the sections were incubated with phalloidin $(1: 200)$ and Hoechst $(1: 1000)$ for an hour. Again, the 
sections were washed with PBST four times ten minutes each prior to mounting.

\section{Imaging and Analysis of Data}

A confocal microscope (Bio-Rad Radiance 2000 MP) was used to scan the whole cochlea section at $20 \times$ first to identify the two specific frequency regions (10 and 28 $\mathrm{kHz}$ ), and then was switched to $40 \times$ to collect images. The images were colorized and merged using the Volocity program. The MOC synaptic terminals and hair cells were quantified for each of the three $\mathrm{OHC}$ rows at the $10 \mathrm{kHz}$ and $28 \mathrm{kHz}$ regions based on confocal images. Statistical computations were performed by Microsoft Excel.

\section{Conflicts of interests}

The authors declare that they have no competing interests.

\section{Additional material}

Additional file 1: Diagram 1: The Medial Olivocochlear Efferent Innervation in the Cochlea. Schematic cross section of the cochlea shows the organ of Corti. Type-I spiral ganglion neurons innervate the inner hair cell, and the outer hair cells are innervated by both type-II spiral ganglion neurons and the medial olivocochlear efferent fibers.

\section{Acknowledgements}

Special thanks to David Jin for his preliminary data, and Aubrey Hawkes for their technical support. This research has been funded in part by grants from the National Institute of Health R01AG024250, R21DC010489, DC004395, DC004086, P30DC004665, and T32DC000022-22.

\section{Author details}

'Department of Otolaryngology, Washington University, St. Louis, MO, 63110, USA. ²Department of Communicative Disorders, Speech and Hearing Center, University of Florida, Gainesville, FL, 32610, USA. ${ }^{3}$ Department of Physiological Science and the Brain Research Institute UCLA, Los Angeles, CA, 90095, USA. ${ }^{4}$ Center for Aging, Washington University, St. Louis, MO, 63110, USA. ${ }^{5}$ The Division of Biology \& Biomedical Science and Neuroscience Program, Washington University, St. Louis, MO, 63110, USA.

\section{Authors' contributions}

$\mathrm{BF}, \mathrm{DL}, \mathrm{AS}$ and $\mathrm{JB}$ designed the experiments, statistical analysis, interpreted the results and drafted the manuscript. $B F, D L, A S$ and $A B C$ carried out the experiments. CLP, DS and JB drafted the manuscript. All authors read and approved the final manuscript.

Received: 1 October 2010 Accepted: 26 November 2010 Published: 26 November 2010

\section{References}

1. Yankner BA, Lu T, Loerch P: The aging brain. Annu Rev Pathol 2008, 3:41-66.

2. Bao J, Ohlemiller KK: Age related loss of spiral ganglion neurons. Hear Res 2009, 264:93-97.

3. Jennings CR, Jones NS: Presbycusis. J Laryngol Otol 2001, 115:171-178.

4. Gates GA, Mills JH: Presbycusis. Lancet 2005, 366:1111-1120.

5. Ohlemiller KK: Contributions of mouse models to understanding of ageand noise-related hearing loss. Brain Res 2006, 1091:89-102.

6. Schuknecht HF, Gacek MR: Cochlear pathology in presbycusis. Ann Otol Rhinol Laryngol 1993, 102:1-16.
7. Schacht J, Hawkins JE: Sketches of otohistory. Part 9: presbycusis. Audiol Neurotol 2005, 10:243-247.

8. Ohlemiller KK, Frisina RD: Clinical characterization of age-related hearing loss and its neural and molecular bases. In Auditory Trauma, Protection and Treatment. Edited by: Schacht J, Popper A, Fay R. New York: SpringerVerlag; 2009:45-194.

9. Stamataki S, Francis HW, Lehar M, May BJ, Ryugo DK: Synaptic alterations at inner hair cells precede spiral ganglion cell loss in aging C57BL/6J mice. Hear Res 2006, 221:104-118.

10. Kim S-H, Frisina DR, Frisina RD: Effects of age on contralateral suppression of distortion product otoacoustic emissions in human listeners with normal hearing. Audiol Neurotol 2002, 7:348-357.

11. Jacobson M, Kim S-H, Romney J, Zhu X, Frisina RD: Contralateral suppression of distortion-product otoacoustic emissions declines with age: a comparison of findings in CBA mice with human listeners. Laryngoscope 2003, 113:1707-1713.

12. Varghese Gl, Zhu X, Frisina RD: Age-related declines in contralateral suppression of distortion product otoacoustic emissions utilizing pure tones in CBA/CAJ mice. Hear Res 2005, 209:60-67.

13. Zhu $\mathrm{H}$, Yang $\mathrm{H}$, Owen MR: Combined microarray analysis uncovers selfrenewal related signaling in mouse embryonic stem cells. Syst Synth Bio 2007, 1:171-181.

14. Kirk EC, Smith DW: Protection from acoustic trauma is not a primary function of the medial olivocochlear efferent system. J Assoc Res Otolaryngol 2003, 4:445-465.

15. Maison SF, Vetter DE, Liberman MC: A novel effect of cochlear efferents: in vivo response enhancement does not require a9 cholinergic receptors. J Neurophysiol 2007, 97:3269-3278.

16. Elgoyhen $A B$, Katz $E$, Fuchs $P A$ : The nicotinic receptor of cochlear hair cells: a possible pharmacotherapeutic target? Biochem Pharmacol 2009, 78:712-719.

17. Rasmussen $\mathrm{GL}$ : The olivary penduncle and other fiber projections of the superior olivary complex. J Comp Neurol 1946, 84:141-219.

18. Warr WB, Guinan JJ Jr: Efferent innervation of the organ of corti: two separate systems. Brain Res 1979, 173:152-155

19. Simmons DD: Development of the inner ear efferent system across vertebrate species. J Neurobiol 2002, 53:228-250.

20. Darrow KN, Maison SF, Liberman MC: Selective removal of lateral olivocochlear efferents increases vulnerability to acute acoustic injury. J Neurophysiol 2007, 97:1775-1785.

21. Le Prell CG, Halsey K, Hughes LF, Dolan DF, Bledsoe SC Jr: Disruption of lateral olivocochlear neurons via a dopaminergic neurotoxin depresses sound-evoked auditory nerve activity. J Assoc Res Otolaryngol 2005, 6:48-62.

22. Maison SF, Emeson RB, Adams JC, Luebke AE, Liberman MC: Loss of aCGRP reduces sound-evoked activity in the cochlear nerve. J Neurophysiol 2003, 90:2941-2949.

23. Bergeron AL, Schrader A, Yang D, Osman AA, Simmons DD: The final stage of cholinergic differentiation occurs below inner hair cells during development of the rodent cochlea. J Assoc Res Otolaryngol 2005, 6:401-415

24. Liberman MC, Brown MC: Physiology and anatomy of single olivocochlear neurons in the cat. Hear Res 1986, 24:17-36.

25. Guinan JJ Jr, Gifford ML: Effects of electrical stimulation of efferent olivocochlear neurons on cat auditory-nerve fibers. I. Rate-level functions. Hear Res 1988, 33:97-114.

26. Guinan JJ Jr, Gifford ML: Effects of electrical stimulation of efferent olivocochlear neurons on cat auditory-nerve fibers. II. Spontaneous rate. Hear Res 1988, 33:115-128.

27. Guinan JJ Jr, Gifford ML: Effects of electrical stimulation of efferent olivocochlear neurons on cat auditory-nerve fibers. III. Turning curves and thresholds at CF. Hear Res 1988, 37:29-46.

28. Liberman MC: Rapid assessment of sound-evoked olivocochlear feedback: suppression of compound action potentials by contralateral sound. Hear Res 1989, 38:47-56.

29. Collet L, Kemp DT, Veuillet E, Duclax R, Moulin A, Morgan A: Effect of contralateral auditory stimuli on active cochlear micromechanical properties in human subjects. Hear Res 1990, 43:251-261.

30. Moulin A, Collet L, Duclax R: Contralateral auditory stimulation alters acoustic distortion products in humans. Hear Res 1993, 65:193-210. 
31. Chery-Croze S, Moulin A, Collet L: Effect of contralateral sound stimulation on distortion product 2f1-f2 in humans: evidence of frequency specificity. Hear Res 1993, 68:53-58.

32. Giraud AL, Garnier S, Micheyl C, Lina G, Chays A, Chery-Croze S: Auditory efferents involved in speech-in-noise intelligibility. Neuroreport 1997 8:1779-1783.

33. Mulders WH, Robertson D: Diverse responses of single auditory afferent fibres to electrical stimulation of the inferior colliculus in guinea-pig. Exp Brain Res 2005, 160:235-244.

34. Vetter DE, Liberman MC, Mann J, Barhanin J, Boulter J, Brown MC, SaffioteKolman J, Heinemann SF, Elgoyhem AB: Role of a9 nicotinic Ach receptor subunits in the development and function of cochlear efferent innervation. Neuron 1999, 23:93-103.

35. Puel JL, Rebillard G: Effect of contralateral sound stimulation on the distortion product $2 \mathrm{~F} 1-\mathrm{F} 2$ : evidence that the medial efferent system is involved. J Acoust Soc Am 1990, 99:3572-3584.

36. Puria S, Guinan JJ Jr, Liberman MC: Efferent-mediated effects of contralateral sound: suppression of CAP versus ear-canal distortion products. J Acoust Soc Am 1996, 99:500-507.

37. Kujawa SG, Liberman MC: Effects of olivocochlear feedback on distortion product otoacoustic emissions in guinea pig. J Assoc Res Otolaryngol 2001, 2(3):268-278.

38. Jacobson M, Kim S-H, Romney J, Zhu X, Frisina RD: Contralateral suppression of distortion-product otoacoustic emissions declines with age: a comparison of findings in CBA mice with human listeners. Laryngoscope 2003, 113:1707-1713.

39. Liberman MC, Puria S, Guinan JJ Jr: The ipsilaterally evoked olivocochlear reflex causes rapid adaptation of the $2 \mathrm{f1}-\mathrm{f} 2$ distortion product otoacoustic emission. J Acoust Soc Am 1996, 99:572-584.

40. Sun X-M, Kim DO: Adaptation of 2f1-2f2 distortion product otoacoustic emission in young-adult and old CBA and C57 mice. J Acoust Soc Am 1999, 105:3399-3409.

41. Mukari SZ, Mamat WH: Medial olivocochlear functioning and speech perception in noise in older adults. Audiol Neurootol 2008, 13:328-334.

42. Feng G, Mellor RH, Bernstein M, Keller-Peck C, Nguyen QT, Wallace M: Imaging neuronal subsets in transgenic mice expressing multiple spectral variants of GFP. Neuron 2000, 28:41-51.

43. Ou HC, Harding GW, Bohne BA: An anatomically based frequency-place map for the mouse cochlea. Hear Res 2000, 145:123-129.

44. Zhu X, Vasilyeva ON, Kim S, Jacobson M, Romney J, Waterman MS, Tuttle D, Frisina RD: Auditory efferent feedback system deficits precede agerelated hearing loss: contralateral suppression of otoacoustic emissions in mice. J Comp Neurol 2007, 503(5):593-604.

45. Jin DX, Lin Z, Lei D, Bao J: The role of glucocorticoids for spiral ganglion neuron survival. Brain Res 2009, 1277:3-11.

46. Finch CE: Neuron atrophy during aging: programmed or sporadic? Trends Neurosci 1993, 16:104-110.

47. Ishida Y, Shirokawa T, Miyaishi O, Komatsu Y, Isobe K: Age-dependant changes in projections from locus coeruleus to hippocampus dentate gyrus and frontal cortex. Eur J Neurosci 2000, 12:1263-1270.

48. Rapp PR, Gallagher M: Preserved neuron number in the hippocampus of aged rats with spatial learning deficits. Proc Natl Acad Sci (USA) 1996, 93:9926-9930.

49. Scheff SW, Price DA: Synaptic pathology in Alzheimer's disease: a review of ultrastructural findings. Neurobiol Aging 2003, 24:1029-1046.

50. Morrison JH, Hof PR: Life and death of neurons in the aging cerebral cortex. Int Rev Neurobiol 2007, 81:41-57.

51. Coggan JS, Grutzendler J, Bishop DL, Cook MR, Gan W, Heym J, Lichtman JW: Age-associated synapse elimination in mouse parasympathetic ganglia. J Neurobiol 2004, 60:214-226.

52. Rattner A, Nathans J: Macular degeneration: recent advances and therapeutic opportunities. Nat Rev Neurosci 2006, 7:860-872.

53. Thrasivoulou C, Soubeyre V, Ridha H, Giuliani D, Giaroni C, Michael GJ, Saffrey MJ, Cowen T: Reactive oxygen species, dietary restriction and neurotrophic factors in age-related loss of myenteric neurons. Aging Cell 2006, 5:247-257.

54. Zimmermann CE, Burgess BJ, Nadol JB: Patterns of degeneration in the human cochlear nerve. Hear Res 1995, 90:192-201.

55. White JA, Burgess BJ, Hall RD, Nadol JB: Pattern of degeneration of the spiral ganglion cell and its processes in the C57BL/6J mouse. Hear Res 2000, 141:2-18.
56. Noben-Trauth K, Zheng QY, Johnson KR: Association of cadherin 23 with polygenic inheritance and genetic modification of sensorineural hearing loss. Nat Genet 2003, 35:21-23.

57. Smith TD, Adams MM, Gallagher M, Morrison JH, Rapp PR: Circuit-specific alterations in synaptophysin immunoreactivity predict spatial learning impairments in aged rats. J Neurosci 2000, 20:6587-6593.

58. Bao J, Lin H, Ouyang Y, Lei D, Osman A, Kim TW, Mei L, Dai P, Ohlemiller KK, Ambron RT: Activity-dependent transcription regulation of PSD-95 by neuregulin-1 and Eos. Nat Neurosci 2004, 7:1250-1258.

doi:10.1186/1750-1326-5-53

Cite this article as: Fu et al:: Age-related synaptic loss of the medial olivocochlear efferent innervation. Molecular Neurodegeneration 2010 5:53.

\section{Submit your next manuscript to BioMed Central and take full advantage of:}

- Convenient online submission

- Thorough peer review

- No space constraints or color figure charges

- Immediate publication on acceptance

- Inclusion in PubMed, CAS, Scopus and Google Scholar

- Research which is freely available for redistribution
C BioMed Central 